\title{
FINE NEEDLE ASPIRATION CYTOLOGY- A SIMPLE AND SENSITIVE DIAGNOSTIC TOOL IN MANAGEMENT OF LYMPHADENOPATHY
}

\author{
Jayasree Sarojinidevi1 ${ }^{1}$ Priya Poickattusseril Vasu², Usha Poothiode ${ }^{3}$ \\ ${ }^{1}$ Assistant Surgeon, Community Health Centre. \\ ${ }^{2}$ Associate Professor (CAP), Department of Pathology, Government Medical College, Kottayam. \\ ${ }^{3}$ Former Professor and HOD, Department of Pathology, Government Medical College, Kottayam.
}

\section{ABSTRACT}

\section{BACKGROUND}

Lymphadenopathy is a frequent problem encountered in clinical practice with majority of the cases self-limiting. However, it can be due to malignant diseases like lymphoproliferative diseases and metastatic lesions, hence an early diagnosis of its aetiology is essential for its management. Fine needle aspiration (FNA) of lymph node is a simple procedure that can be performed in outpatient clinic and FNA cytology provides early diagnosis.

Aim- To categorise the various causes of lymphadenopathy and assess the efficiency of FNAC as a dependable, cost effective, efficacious diagnostic method in lymph node lesions.

\section{MATERIALS AND METHODS}

This IRB approved prospective study was carried out in a tertiary care teaching centre. Lymph node FNAC diagnoses of 70 patients were correlated with the histopathological diagnosis, which is considered as the gold standard.

\section{RESULTS \\ Lymphadenopathy due to non-neoplastic diseases (55.7\%) outnumbered the neoplastic diseases (44.3\%). Nonspecific reactive lymphadenopathy was the most common lymph node pathology (31.4\%) followed by metastatic lymphadenopathy (22.9\%). Acid fast bacilli were demonstrated by Auramine-rhodamine staining in all cases of suppurative granulomatous lymphadenitis. \\ Discussion- Diagnostic sensitivity, specificity, positive predictive value, negative predictive value and efficiency of FNAC to diagnose nonspecific reactive lymphadenopathy were 100\%, 95.8\%, 91.6\%, 100\%, and 97.1\% respectively. The diagnostic sensitivity, specificity, positive predictive value, negative predictive value and efficiency of FNAC were $100 \%$ in case of chronic granulomatous lymphadenitis, suppurative granulomatous lymphadenitis, suppurative lymphadenitis, fungal lymphadenitis, and Hodgkin lymphoma. The overall diagnostic efficiency of FNAC in this study was $97 \%(68 / 70)$ and the overall discordance rate was $3 \%(2 / 70)$.}

\section{CONCLUSION}

FNAC is an effective, inexpensive, rapid and simple tool which renders a prompt diagnosis for the management of patients with lymphadenopathy and surgical excision biopsy can be avoided in a good number of cases. Use of ancillary staining studies in FNA smears improves the accuracy of this diagnostic tool.

\section{KEYWORDS}

Lymphadenopathy, Fine Needle Aspiration Cytology, Lymphoma, Granulomatous Lymphadenitis.

HOW TO CITE THIS ARTICLE: Sarojinidevi J, Vasu PP, Poothiode U. Fine needle aspiration cytology- A simple and sensitive diagnostic tool in management of lymphadenopathy. J. Evolution Med. Dent. Sci. 2017;6(35):2915-2920, DOI: $10.14260 /$ Jemds/2017/628

\section{BACKGROUND \\ Lymph nodes are an important part of immune system as the components of peripheral or secondary lymphoid organs. Normally children and adults have well-developed lymph nodes with numerous follicles. A reduction in the number of follicles with replacement either by fat as in axillary lymph nodes or connective tissue as in case of inguinal lymph nodes is common in the elderly. Lymphadenopathy is one of the}

Financial or Other, Competing Interest: None.

Submission 24-03-2017, Peer Review 18-04-2017,

Acceptance 24-04-2017, Published 01-05-2017.

Corresponding Author:

Dr. Priya Poickattusseril Vasu,

Associate Professor (CAP),

Department of Pathology,

Government Medical College,

Kottayam.

E-mail: drpvpriya@yahoo.com

DOI: $10.14260 /$ jemds $/ 2017 / 628$

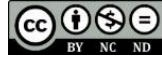

commonest clinical presentations of all age groups encountered in the clinical practice. The cause of it may vary from non-neoplastic to neoplastic diseases. ${ }^{[1]}$

In 1904, Greig et al published a paper on the diagnosis of sleeping sickness in 15 patients by recognising actively mobile trypanosomes in cover-glass preparations taken from cervical lymph nodes.[2] Guthrie systematically performed lymph node aspiration and reported about the diagnostic applications of needle aspiration in 1921.[3] Martin et al in 1930 published their experience on detection of metastatic tumour cells in lymph nodes by fine needle aspiration cytology (FNAC).[4] As the fine needle aspiration can be performed in outpatient clinic causes minimal trauma and complications in a patient and early availability of report within 24 hours, soon it gained popularity. FNAC of lymph nodes had proven to be an easy and quick diagnostic tool which helps to differentiate between malignant and inflammatory diseases, thus it helps in patient management. ${ }^{[5]}$ Aspirated material may be used in ancillary 
tests such as cytochemical staining to support the cytological diagnosis.

The principal indication for FNA study is the persistent enlargement of lymph nodes, and the purpose of the procedure is to establish the cause of lymphadenopathy which cannot be reliably diagnosed on clinical grounds. Usual non-neoplastic conditions causing lymphadenopathy are infections and inflammations, but persistent enlargement of lymph nodes can be encountered in autoimmune disorders and hypersensitivity reactions also. Chronic lymphadenitis, more often referred to as reactive hyperplasia of lymph nodes is the commonest cause of lymph node enlargement. Clinically acute lymphadenitis usually appears as red, hot and tender swellings. Tuberculosis, brucellosis, fungi, pneumocystis carinii, sarcoidosis, and rarely lymphomas cause granulomatous lymphadenitis.[1] Lymph node granulomatous inflammation is reported in association with metastasis from squamous cell carcinoma, pulmonary small cell carcinoma, gastric carcinoma, and papillary carcinoma thyroid.[1,6-8] Very rarely tuberculous lymphadenitis shows features of suppurative lymphadenitis such as only necrotic material and neutrophils.[9]

The lymph node architecture is important in subclassification of some lymphomas, and it is the main limitation of use of lymph node FNA to render a primary diagnosis of lymphoma. In FNA whenever the cytomorphological features are suggestive of a diagnosis of lymphoproliferative disorder, excision, of a lymph node is recommended for confirmation and subclassification.[10] In cytology the cornerstone of the cytodiagnosis of Hodgkin lymphoma is the presence of classic Reed-Sternberg cells in an appropriate polymorphous cellular background of eosinophils, lymphocytes, plasma cells and histiocytes.[11-13] Metastatic neoplasm is a far more common cause for lymph node enlargement than lymphoma, especially in patients older than 50 years. FNA is considered as a reliable method of diagnosing metastatic diseases, a task which is much easier than diagnosing lymphomas. It may provide clues for occult primaries and at times it also surprises the clinician who never considered the possibility of a malignancy in a particular patient.[1]

\section{Aim and Objectives}

1. To categorise various lesions causing lymphadenopathy by fine needle aspiration cytology (FNAC).

2. To correlate the cytological findings with the histopathological changes in lymph nodes.

3. To assess the value of FNAC as a dependable, cost effective, efficacious diagnostic method in lymph node lesions.

\section{MATERIALS AND METHODS}

This study was conducted in our institution after the approval of institutional ethics committee.

Patients with lymph node enlargement who underwent lymph node FNAC and subsequent lymph node biopsy for histopathological study in our institution during the study period of 18 months from April 2014 were included in this study. Patients were selected randomly, with no preference given to age, sex or any other criteria. FNAC was carried out in our institution with all aseptic precautions by nonaspiration technique using 23 gauge needles without any local anaesthesia. A minimum of two or three smears were prepared using the aspirated material, one of which is air dried for doing Giemsa staining and others were immediately fixed in 95\% ethyl alcohol for Papanicolaou staining. Special staining such as mucicarmine for mucin, and auraminerhodamine staining for mycobacterium tuberculous bacilli were performed whenever necessary. The cases in which the aspirate was scanty were subjected to a second FNAC. Later the lymph nodes were excised for histopathological study in the Department of Pathology of our institution. Cytological results were compared with histopathological diagnosis, to assess the accuracy of FNAC results. Diagnostic sensitivity, specificity, positive predictive value, negative predictive value and efficiency of the FNAC were calculated from the data obtained.

\section{RESULTS}

During the study period of 18 months a total of two hundred and sixteen patients with clinically significant lymph node enlargement underwent FNAC, of this only 70 cases had undergone subsequent lymph node excision biopsy for histopathological study in our institution and which were selected for this study. The study group included 36 female (51.4\%) and 34 male (48.6\%) patients. Age of patients ranged from 2 to 77 years with mean age of 42.66 years (42.66 \pm 19.31 ) and majority were in the fifth and sixth decades (22.9\% each).[Table. 1 and Fig. 1].

\begin{tabular}{|c|c|c|c|c|c|c|c|c|c|}
\hline $\begin{array}{c}\text { Age in } \\
\text { Decades }\end{array}$ & $\mathbf{1}$ & $\mathbf{2}$ & $\mathbf{3}$ & $\mathbf{4}$ & $\mathbf{5}$ & $\mathbf{6}$ & $\mathbf{7}$ & $\mathbf{8}$ & Total \\
\hline $\begin{array}{c}\text { Number of } \\
\text { Cases }\end{array}$ & 6 & 7 & 5 & 8 & 16 & 16 & 10 & 2 & $\mathbf{7 0}$ \\
\hline Percent & 8.6 & 10 & 7.1 & 11.4 & 22.9 & 22.9 & 14.3 & 2.9 & $\mathbf{1 0 0}$ \\
\hline \multicolumn{7}{|c|}{ Table 1. Age Distribution of Patients } \\
\hline
\end{tabular}

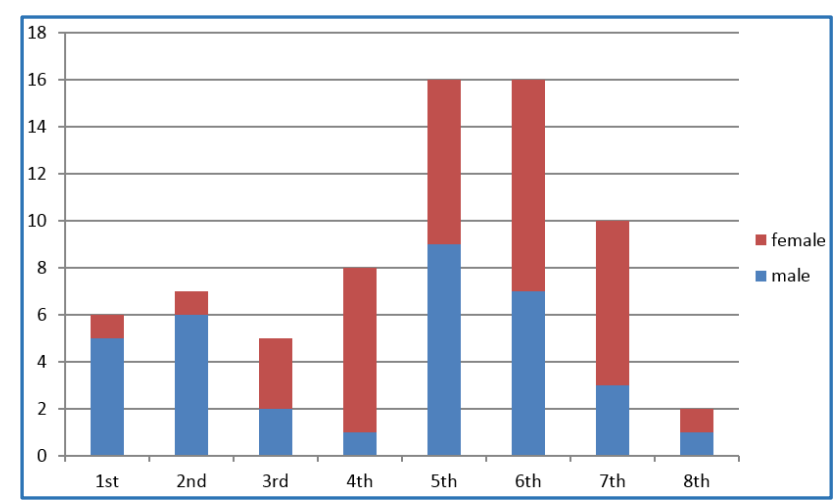

Figure 1. Age and Gender Distribution of Patients

In $41(58.5 \%)$ cases, lymph node enlargement was present for more than 2 months. FNA was taken from cervical lymph nodes in 59 (84.2\%) cases, which include one case of level 1 lymph node, two cases each of level 2 and level 5 lymph nodes and 54 cases were contributed by level 3 and 4 lymph nodes together. Other sites from which study material was collected were axillary $(n=9,13 \%)$, hilar $(n=1,1.4 \%)$ and retroperitoneal $(\mathrm{n}=1,1.4 \%$ ) lymph nodes. Based on cytomorphological features observed in the aspirate smears, 41 cases $(58.6 \%)$ were diagnosed as non-neoplastic lesions and 29 as neoplastic lesions (41.4\%) [Table 2]. 


\begin{tabular}{|c|c|c|c|c|c|c|}
\hline & Cytology & Frequency & Percent & Histopathology & Frequency & Percent \\
\hline NRL & \multirow{7}{*}{$\begin{array}{c}\text { Non-Neoplastic } \\
\text { Diseases } \\
(\mathrm{N}=41)\end{array}$} & 24 & 34.3 & \multirow{7}{*}{$\begin{array}{c}\text { Non-Neoplastic } \\
\text { Diseases } \\
(\mathrm{N}=39)\end{array}$} & 22 & 31.4 \\
\hline CGL & & 7 & 10.0 & & 7 & 10.0 \\
\hline SGL & & 6 & 8.6 & & 6 & 8.6 \\
\hline SUL & & 1 & 1.4 & & 1 & 1.4 \\
\hline FUL & & 1 & 1.4 & & 1 & 1.4 \\
\hline DPL & & 1 & 1.4 & & 2 & 2.9 \\
\hline RDD & & 1 & 1.4 & & 0 & 0.0 \\
\hline ML & \multirow{3}{*}{$\begin{array}{l}\text { Neoplastic Diseases } \\
\qquad(\mathrm{N}=29)\end{array}$} & 16 & 22.9 & \multirow{3}{*}{$\begin{array}{l}\text { Neoplastic } \\
\text { Diseases } \\
(\mathrm{N}=31)\end{array}$} & 16 & 22.9 \\
\hline NHL & & 11 & 15.7 & & 13 & 18.5 \\
\hline HD & & 2 & 2.9 & & 2 & 2.9 \\
\hline Total & & 70 & 100 & & 70 & 100.0 \\
\hline
\end{tabular}

NRL- nonspecific reactive lymphadenopathy, CGL- chronic granulomatous lymphadenitis, SGL- suppurative granulomatous lymphadenitis, SUL- suppurative lymphadenitis, FL- fungal lymphadenitis, DPL- dermatopathic lymphadenitis, RDD- RosaiDorfman disease, ML- metastatic lymphadenopathy, NHL- Non-Hodgkin lymphoma, HD- Hodgkin lymphoma.

\section{Table 2. Diagnosis of Lymph Node FNAC and Histopathology $(n=70)$}

In this study, nonspecific reactive lymphadenopathy predominated among the non-neoplastic lesions while metastatic lymphadenopathy predominated among the neoplastic lesions. A total of 13 cases showed epithelioid granuloma in aspirate smears, of which 7 cases were diagnosed as chronic granulomatous lymphadenitis and 6 cases as suppurative granulomatous lymphadenitis. Auramine-rhodamine staining was done on aspirate smears to demonstrate mycobacterium tuberculosis bacilli; all cases of suppurative granulomatous lymphadenitis $(n=6,100 \%)$ gave positive result, while all cases of chronic granulomatous lymphadenitis $(n=7)$ showed negative result. In one case, budding yeast forms of histoplasma was observed in aspirate smears and which was diagnosed as fungal lymphadenitis. Lymphoproliferative disorders comprised 15 cases which included 11 Non-Hodgkin lymphoma and 2 Hodgkin lymphoma cases. Metastatic tumours causing lymphadenopathy constituted 16 cases in this study.
In $26(37.1 \%)$ cases excised lymph node was more than 2 $\mathrm{cm}$ in diameter. In 6 cases $(8.6 \%)$ lymph nodes were matted. Consistency of lymph nodes was firm in 53 cases $(75.7 \%)$, hard in 16 cases $(22.9 \%)$ and soft in 1 case (1.4\%). Based on the histomorphological features, 39 patients were diagnosed to have non-neoplastic lesions and 31 had neoplastic lesions. [Table 2] Predominating type of non-neoplastic and neoplastic lesions of lymph node were as same as that we observed in FNAC. In cytologically diagnosed case of fungal lymphadenitis, budding yeast form of Histoplasma was demonstrated in tissue sections by Gomori's Methenamine silver staining. Cytological results of 70 cases were compared with histopathological diagnosis [Table 3] and statistical analysis for all non-neoplastic and neoplastic diseases was done [Table 4 and 5].

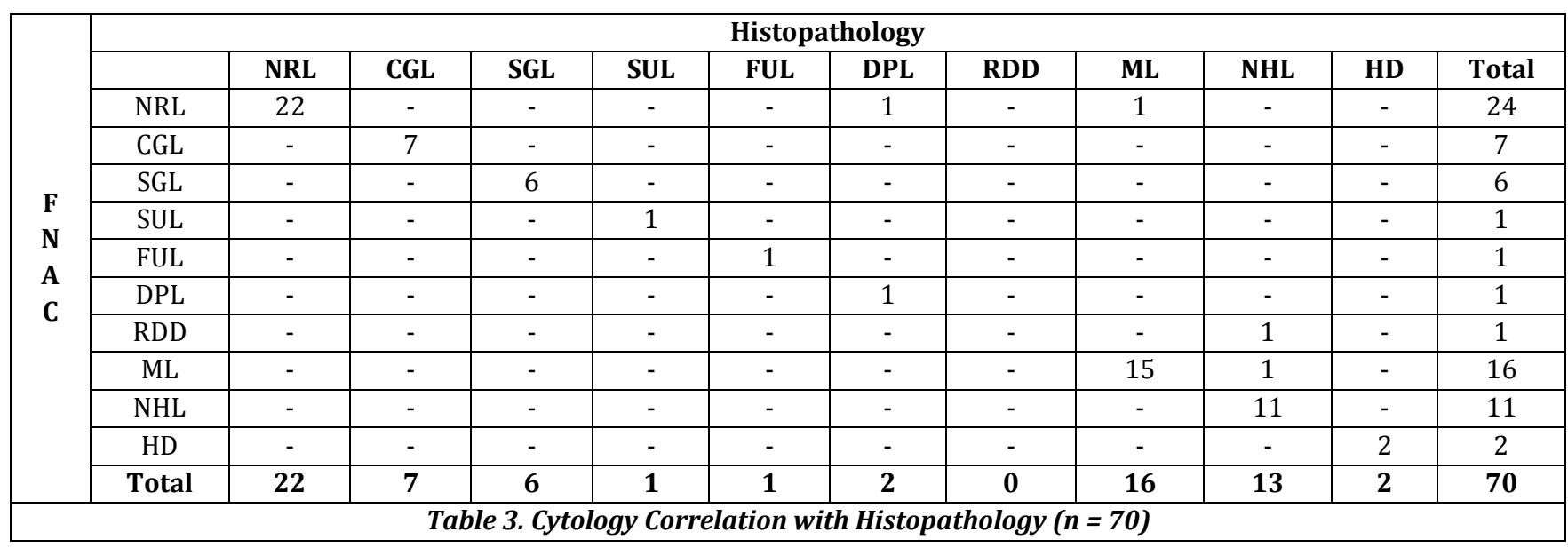

\begin{tabular}{|c|c|c|c|c|c|}
\hline Diagnosis & FNAC & \multicolumn{2}{|c|}{ Histopathology } & \multirow{2}{*}{ TOTAL } & \multirow{2}{*}{$\begin{array}{c}\text { Predictive Value ( PV)/ } \\
\text { Diagnostic Accuracy }\end{array}$} \\
\hline \multirow{5}{*}{$\begin{array}{l}\text { Nonspecific Reactive } \\
\text { Lymphadenopathy }\end{array}$} & Result & Positive & Negative & & \\
\hline & Positive & 22 & 2 & 24 & 91.6\% (Positive PV) \\
\hline & Negative & 0 & 46 & 46 & $100 \%$ (Negative PV) \\
\hline & Total & 22 & 48 & 70 & \\
\hline & $\begin{array}{l}\text { Sensitivity/ } \\
\text { Specificity }\end{array}$ & $\begin{array}{c}100 \% \\
\text { (Sensitivity) }\end{array}$ & $\begin{array}{c}95.8 \% \\
\text { (Specificity) }\end{array}$ & & $\begin{array}{c}97.1 \% \\
\text { (Diagnostic Accuracy) }\end{array}$ \\
\hline
\end{tabular}




\begin{tabular}{|c|c|c|c|c|c|}
\hline \multirow{4}{*}{$\begin{array}{l}\text { Chronic Granulomatous } \\
\text { Lymphadenitis }\end{array}$} & Positive & 7 & 0 & 7 & 100\% (Positive) \\
\hline & Negative & 0 & 63 & 63 & 100\% (Negative) \\
\hline & Total & 7 & 63 & 70 & \\
\hline & $\begin{array}{l}\text { sensitivity/ } \\
\text { specificity }\end{array}$ & $\begin{array}{c}100 \% \\
\text { (Sensitivity) }\end{array}$ & $\begin{array}{c}100 \% \\
\text { (Specificity) }\end{array}$ & & $\begin{array}{c}100 \% \\
\text { (Diagnostic Accuracy) }\end{array}$ \\
\hline \multirow{4}{*}{$\begin{array}{l}\text { Suppurative } \\
\text { Granulomatous } \\
\text { Lymphadenitis }\end{array}$} & Positive & 6 & 0 & 6 & 100\% (Positive PV) \\
\hline & Negative & 0 & 64 & 64 & 100\% (Negative PV) \\
\hline & Total & 6 & 64 & 70 & \\
\hline & $\begin{array}{l}\text { Sensitivity/ } \\
\text { Specificity }\end{array}$ & $\begin{array}{c}100 \% \\
\text { (Sensitivity) }\end{array}$ & $\begin{array}{c}100 \% \\
\text { (Specificity) }\end{array}$ & & $\begin{array}{c}100 \% \\
\text { (Diagnostic Accuracy) }\end{array}$ \\
\hline \multirow{4}{*}{$\begin{array}{c}\text { Suppurative } \\
\text { Lymphadenitis }\end{array}$} & Positive & 1 & 0 & 1 & 100\% (Positive PV) \\
\hline & Negative & 0 & 69 & 69 & 100\% (Negative PV) \\
\hline & Total & 1 & 69 & 70 & \\
\hline & $\begin{array}{l}\text { Sensitivity/ } \\
\text { Specificity }\end{array}$ & $\begin{array}{c}100 \% \\
\text { (Sensitivity) }\end{array}$ & $\begin{array}{c}100 \% \\
\text { (Specificity) }\end{array}$ & & $\begin{array}{c}100 \% \\
\text { (Diagnostic accuracy) }\end{array}$ \\
\hline \multirow{4}{*}{$\begin{array}{c}\text { Fungal } \\
\text { Lymphadenitis }\end{array}$} & Positive & 1 & 0 & 1 & 100\% (Positive PV) \\
\hline & Negative & 0 & 69 & 69 & 100\% (Negative PV) \\
\hline & Total & 1 & 69 & 70 & \\
\hline & $\begin{array}{l}\text { Sensitivity/ } \\
\text { Specificity }\end{array}$ & $\begin{array}{c}100 \% \\
\text { (Sensitivity) }\end{array}$ & $\begin{array}{c}100 \% \\
\text { (Specificity) }\end{array}$ & & $\begin{array}{c}100 \% \\
\text { (Diagnostic accuracy) }\end{array}$ \\
\hline \multirow{4}{*}{$\begin{array}{l}\text { Dermatopathic } \\
\text { Lymphadenitis }\end{array}$} & Positive & 1 & 0 & 1 & 100\% (Positive PV) \\
\hline & Negative & 1 & 68 & 69 & 98.5\% (Negative PV) \\
\hline & Total & 2 & 68 & 70 & \\
\hline & $\begin{array}{l}\text { Sensitivity/ } \\
\text { Specificity }\end{array}$ & $50 \%$ (Sensitivity) & $\begin{array}{c}100 \% \\
\text { (Specificity) }\end{array}$ & & $\begin{array}{c}98.5 \% \\
\text { (Diagnostic accuracy) }\end{array}$ \\
\hline \multicolumn{6}{|c|}{ Analysis for Non-1 } \\
\hline
\end{tabular}

\begin{tabular}{|c|c|c|c|c|c|}
\hline Diagnosis & FNAC & \multicolumn{2}{|c|}{ Histopathology } & \multirow{2}{*}{ Total } & \multirow{2}{*}{$\begin{array}{c}\text { Predictive Value (PV)/ } \\
\text { Diagnostic Accuracy }\end{array}$} \\
\hline \multirow{5}{*}{$\begin{array}{c}\text { Metastatic } \\
\text { lymphadenopathy }\end{array}$} & Result & Positive & Negative & & \\
\hline & Positive & 15 & 1 & 24 & 93.7\%(Positive PV) \\
\hline & Negative & 1 & 53 & 46 & 98.1\%(Negative PV) \\
\hline & Total & 16 & 54 & 70 & \\
\hline & $\begin{array}{l}\text { Sensitivity/ } \\
\text { Specificity }\end{array}$ & $\begin{array}{c}93.7 \% \\
\text { (Sensitivity) }\end{array}$ & $\begin{array}{c}98.1 \% \\
\text { (Specificity) }\end{array}$ & & $\begin{array}{c}97.1 \% \\
\text { (Diagnostic Accuracy) }\end{array}$ \\
\hline \multirow{4}{*}{ Non-Hodgkin lymphoma } & Positive & 11 & 0 & 11 & 100\%(Positive PV) \\
\hline & Negative & 2 & 57 & 59 & 96.6\%(Negative PV) \\
\hline & Total & 13 & 57 & 70 & \\
\hline & $\begin{array}{l}\text { Sensitivity/ } \\
\text { Specificity }\end{array}$ & $\begin{array}{c}84.6 \% \\
\text { (Sensitivity) }\end{array}$ & $\begin{array}{c}100 \% \\
\text { (Specificity) }\end{array}$ & & $\begin{array}{c}97.1 \% \\
\text { (Diagnostic Accuracy) }\end{array}$ \\
\hline \multirow{4}{*}{ Hodgkin lymphoma } & Positive & 2 & 0 & 2 & $100 \%$ (Positive PV) \\
\hline & Negative & 0 & 68 & 68 & 100\%(Negative PV) \\
\hline & Total & 2 & 68 & 70 & \\
\hline & $\begin{array}{l}\text { Sensitivity/ } \\
\text { Specificity }\end{array}$ & $\begin{array}{c}100 \% \\
\text { (Sensitivity) }\end{array}$ & $\begin{array}{c}100 \% \\
\text { (Specificity) }\end{array}$ & & $\begin{array}{c}100 \% \\
\text { (Diagnostic Accuracy) }\end{array}$ \\
\hline & Table 5. Stati & Analysis for & plastic Disea. & ymp & \\
\hline
\end{tabular}

\section{DISCUSSION}

FNAC plays a significant role in patient management in developing countries like India, as it is a simple procedure which can be safely performed in outpatient clinic and has almost no complications.[1] The frequent involvement in regional as well as systemic diseases and the easy accessibility make lymph node as a commonest site for FNAC. The primary objective in the assessment of smears from enlarged lymph node is to distinguish between nonneoplastic and neoplastic lesions of lymph node. The diagnosis made based on the cytological findings is often taken as the final diagnosis of the illness in clinical practice, and there is no further correlation with histopathology, especially in patients having advanced malignancies. In our cytology laboratory, a total of 216 patients were investigated for lymphadenopathy by FNAC over a period of 18 months, of which 70 (32.4\%) patients underwent subsequent lymph node biopsy during our study period, for confirmation of diagnosis. Age of the study group had a wide range, from 2 to 77 years with mean age of 42.66 years (42.66 \pm 19.31 ) and male to female ratio was $0.94: 1$. Non-neoplastic diseases were diagnosed in the lymph nodes by histopathology in 39 cases and by FNAC in 41 cases.

In this study, most frequent non-neoplastic lymph node disease diagnosed by both histopathology and FNAC was nonspecific reactive lymphadenopathy, 22 and 24 cases respectively. All cases of nonspecific reactive lymphadenopathy diagnosed in biopsy study were correctly detected in prior FNAC also. One case each of metastatic lymphadenopathy and dermatopathic lymphadenitis was 
misinterpreted in FNAC as nonspecific reactive lymphadenopathy. So the diagnostic sensitivity, specificity, positive predictive value and negative predictive value of FNAC for the diagnosis of nonspecific reactive lymphadenopathy were $100 \%, 95.8 \%, 91.6 \%$ and $100 \%$ respectively. A diagnostic test is considered satisfactory if its sensitivity and specificity are around $90 \%$. In this study, the diagnostic accuracy of FNAC for nonspecific reactive lymphadenopathy was $97.1 \%$, which was in agreement with the results of Gupta et al.[14] who got $96.2 \%$ diagnostic accuracy, but it was much higher than that reported by Nasreen et al[15] (85\%).

In the current study, all the cases of chronic granulomatous lymphadenitis as well as suppurative granulomatous lymphadenitis diagnosed in FNAC were found to be correct by the subsequent biopsy study. So in case of granulomatous lymphadenitis, the diagnostic sensitivity, specificity, positive predictive value and negative predictive value of FNAC was found to be $100 \%$. The diagnostic efficiency of FNAC in case of granulomatous lymphadenitis was $100 \%$ in our study, while it was $70 \%$ and $97.5 \%$ in the experience of Nasreen et $\mathrm{al}^{[15]}$ and Gupta et $\mathrm{al}^{[14]}$ respectively. On examination of Auramine-rhodamine stained lymph node aspirate smears by fluorescent microscope under ultraviolet illumination, we could identify acid fast bacilli as bright fluorescing rods against a dark background in all the six cases $(100 \%)$ of suppurative granulomatous lymphadenitis, while no bacilli could be demonstrated in chronic granulomatous lymphadenitis cases.

Suppurative lymphadenitis without any granuloma was diagnosed in one patient by FNAC and which was negative for acid fast bacilli, later histopathology confirmed this diagnosis. Fungal lymphadenitis due to Histoplasma was suggested in a 24-year-old male with enlarged supraclavicular lymph node, it was found to be correct by biopsy study and Gomori methenamine-silver staining. Subsequent workup in this case proved that he was an immune-deficient patient. The diagnostic sensitivity, specificity, positive predictive value, negative predictive value and efficiency of FNAC were 100\% in case of suppurative and fungal lymphadenitis

Dermatopathic lymphadenitis represents a T-cell response to skin antigens processed and presented by interdigitating dendritic cells.[13] In histopathology two cases of dermatopathic lymphadenitis were diagnosed in this study. One of this was correctly detected by FNAC in a 15-year-old male patient. Second case was misinterpreted as reactive lymphadenopathy in a 58-year-old male patient. So in our experience FNAC as a diagnostic tool for the diagnosis of dermatopathic lymphadenitis had 50\% sensitivity, 100\% specificity, $100 \%$ positive predictive value, $98.5 \%$ negative predictive value and $98.5 \%$ diagnostic efficiency.

Any malignant diseases of lymph node can cause total or partial effacement of its architecture and the later frequently creates problem for FNA diagnosis.[16] In this study neoplastic diseases of lymph node were diagnosed by histopathology in 31 cases while by FNAC in 29 cases only. Histopathology proved metastatic lymphadenopathy in 16 patients and lymphoproliferative diseases in 15 patients. Histological types of metastatic lesions proved in the biopsy study include 8 cases of squamous cell carcinoma, 3 cases of papillary carcinoma thyroid and 1 case each of anaplastic carcinoma thyroid, small cell carcinoma of lung, breast carcinoma, poorly differentiated carcinoma and adenocarcinoma. All these biopsy proven metastatic lesions were correctly detected in FNAC also as metastatic lymphadenopathy except one. Single case of squamous cell carcinoma metastasis with partial effacement of cervical lymph node architecture in a 47-year-old male, was misinterpreted in FNAC as nonspecific reactive lymphadenopathy. So in this study, the diagnostic sensitivity, specificity, positive predictive value and negative predictive value of FNAC as a diagnostic tool for detecting metastatic lymphadenopathy were found to be $93.7 \%, 98.1 \%$, 93.7\% and $98.1 \%$ respectively. The diagnostic efficiency of FNAC was $97.1 \%$ in our experience, while it was $100 \%$ and $98.75 \%$ in the experience of Nasreen et al[15] and Gupta et al.[14] respectively.

Among the 15 lymphoproliferative diseases diagnosed by lymph node biopsy, majority were Non-Hodgkin lymphomas. Of the 13 biopsy confirmed Non-Hodgkin lymphomas, 11 were correctly detected in FNAC. In a 77-year-old female patient, axillary lymphadenopathy due to Non-Hodgkin lymphoma was misinterpreted in FNAC as metastatic lymphadenopathy. Another case of Non-Hodgkin lymphoma in a 43-year-old male was misdiagnosed in lymph node FNAC as Rosai-Dorfman disease. It is reported that focal RosaiDorfman disease like changes can sometimes be seen in lymph nodes involved by lymphoproliferative diseases.[17] So FNAC had $84.6 \%$ sensitivity, $100 \%$ specificity, $100 \%$ positive predictive value and $96.6 \%$ negative predictive value for the diagnosis of Non-Hodgkin lymphoma. The diagnostic efficiency of FNAC was $97.1 \%$ in our study, while it was $75 \%$ and $100 \%$ in the reports of Nasreen et al ${ }^{[15]}$ and Gupta et al ${ }^{[14]}$ respectively.

In 2 patients FNAC from enlarged lymph node showed Reed-Sternberg cells in a background of plasma cells, histiocytes, eosinophils, and lymphocytes. In both cases, diagnosis of Hodgkin lymphoma was suggested in FNAC and the subsequent biopsy study proved that the cytological diagnosis was correct. In the current study, the diagnostic sensitivity, specificity, positive predictive value, negative predictive value and efficiency of FNAC were $100 \%$ in case of Hodgkin lymphoma. The diagnostic efficiency of FNAC was $100 \%$ in our study, which was in agreement with the results of Gupta et al[14] who got $100 \%$ diagnostic efficiency, but it was much higher than that reported by Nasreen et al[15] (77.8\%).

The primary objective of doing lymph node FNAC in a patient having lymphadenopathy is to distinguish between its non-neoplastic and neoplastic lesions. The cytomorphological and histomorphological diagnosis of the corresponding excised lymph nodes were compared in this study. All the neoplastic cases $(n=29,100 \%)$ detected in FNAC were proved to be neoplastic in histopathology also (True positive). Among the 41 non-neoplastic cases identified in FNAC, 39 (95.1\%) were confirmed as non-neoplastic in histopathology (true negative) while 2 cases (4.9\%) were proved as neoplastic (false negative). So in this study, the overall diagnostic sensitivity, specificity, positive predictive value and negative predictive value of FNAC were 93.5\%, 100\%, $100 \%$ and $95.1 \%$ respectively. The overall diagnostic accuracy of this study was $97 \%(68 / 70)$ and the overall discordance rate was $3 \%(2 / 70)$. 


\section{CONCLUSION}

In our experience, the excision biopsy study of significantly enlarged lymph node showed that its causes include both non-neoplastic and neoplastic diseases in a ratio of 1: 1.2 . Since only $32.4 \%$ of the FNAC diagnosed lymphadenopathy cases needed subsequent excision biopsy study and majority of which were proved to have non-neoplastic lesions, the most common cause of lymph node enlargement in our clinical setting was non-neoplastic lesions of lymph node. The most common abnormality diagnosed in histopathology of excised lymph nodes was nonspecific reactive lymphadenopathy $(22 / 70,31.4 \%)$. Diagnostic sensitivity, specificity, positive predictive value, negative predictive value and efficiency of FNAC to diagnose nonspecific reactive lymphadenopathy were $100 \%, 95.8 \%, 91.6 \%, 100 \%$, and $97.1 \%$ respectively. A diagnostic test is considered satisfactory if its sensitivity and specificity are around $90 \%$.

In the current study, the diagnostic sensitivity, specificity positive predictive value, negative predictive value and efficiency of FNAC were $100 \%$ in case of chronic granulomatous lymphadenitis, suppurative granulomatous lymphadenitis, suppurative lymphadenitis, fungal lymphadenitis, and Hodgkin lymphoma.

The overall diagnostic efficiency of FNAC in this study was $97 \%(68 / 70)$ and the overall discordance rate was $3 \%$ (2/70). Use of ancillary staining studies in FNA smears improves the accuracy of this diagnostic tool. So FNAC is an effective, inexpensive, rapid and simple tool which renders a prompt diagnosis for the management of patients with lymphadenopathy and surgical excision biopsy can be avoided in a good number of cases.

\section{ACKNOWLEDGEMENT}

We would like to acknowledge Dr. Sankar S, Professor and Head of the Department of Pathology for giving continuous encouragement to us and all consultant surgeons of our institution for providing material for this study. There is no conflict of interest which is associated with this publication and that there has been no financial support for this work that could have influenced its outcome.

\section{REFERENCES}

[1] Caraway NP, Katz RL. Lymph nodes. In: Koss LG, ed. Koss diagnostic cytology and its histopathologic bases. $5^{\text {th }}$ edn. Philadelphia: Lippincott 2006:1186-225.

[2] Greig EDW, Gray ACH. Note on the lymphatic glands in sleeping sickness. Br Med J 1904;1(2265):252.

[3] Guthrie CG. Gland puncture as a diagnostic measure. Bull Johns Hopkins Hosp 1921;32:266-9.
[4] Martin HE, Ellis EB. Biopsy by needle puncture and aspiration. Ann Surg 1930;92(2):169-81.

[5] Steel BL, Schwartz MR, Ramzy I. Fine needle aspiration biopsy in the diagnosis of lymphadenopathies in 1103 patients. Role, limitations and analysis of diagnostic pitfalls. Acta Cytol 1995;39(1):76-81.

[6] Kamiyoshihara M, Hirai T, Kawashima 0, et al. Pulmonary small cell carcinoma associated with sarcoid reactions: report of a case. Surg Today 1999;29(4):382-84.

[7] Kojima M, Nakamura S, Fugisaki M, et al. Sarcoid -like reaction in the regional lymph nodes and spleen in gastric carcinoma. A clinicopathologic study of five cases. Gen Diagn Pathol 1997;142:347-52.

[8] Yamauchi M, Inoue D, Fukunaga Y, et al. A case of sarcoid reaction associated with papillary thyroid carcinoma. Thyroid 1997;7(6):901-3.

[9] Das DK. Fine-needle aspiration cytology in the diagnosis of tuberculous lesions. Lab Med 2000;31:625-32.

[10] Hehn ST, Grogan TM, Miller TP. Utility of fine-needle aspiration as a diagnostic technique in lymphoma. J Clin Oncol 2004;22(15):3046-52.

[11] Das DK, Gupta SK, Datta BN, et al. Fine needle aspiration cytodiagnosis of Hodgkin lymphoma and its subtypes. I. Scope and limitations. Acta Cytol 1990;34(3):329-36.

[12] Malaker D, Jajoo ILN, Gupta OP, et al. A clinical evaluation of fine needle aspiration cytology in the diagnosis of lymphadenopathy. Ind $J$ Tuberc 1991;38(1):17-9.

[13] Rosai J. Lymph nodes. In: Rosai J, ed. Rosai and Ackerman's surgical pathology. $10^{\text {th }}$ edn. Vol. 2. China: Elsevier 2011:1772-900.

[14] Gupta ML, Singh K. Correlation of fine needle aspiration cytology lymph node with histopathological diagnosis. Int J Res Med Sci 2016;4(11):4719-23.

[15] Hafez NH, Tahoun NS. Reliability of fine needle aspiration cytology (FNAC) as a diagnostic tool in cases of cervical lymphadenopathy. Journal of Egyptian National Cancer Institute 2011;23(3):105-14.

[16] Mendon ME. Fine needle aspiration cytology lymph nodes. Progress in Diagnostic Cytology 1999;32(3):410-11.

[17] Lu D, Estalill OC, Manning JT, et al. Sinus histiocytosis with massive lymphadenopathy and malignant lymphoma involving the same lymph node: a report of four cases and review of the literature. Mod Pathol 2000;13(4):414-9. 